\title{
Contribution to the Economic and Optimal Planning of Multi-GED and a FACTS in a Distribution Network by Genetics Algorithms
}

\author{
Arouna Oloulade ${ }^{1, *}$, Adolphe Moukengue Imano ${ }^{2}$, François-Xavier Fifatin ${ }^{3}$, \\ Mahamoud Tanimomon ${ }^{1}$, Akouèmaho Richard Dansou ${ }^{1}$, Ramanou Badarou ${ }^{3}$, Antoine Vianou ${ }^{4}$ \\ ${ }^{1}$ Electrotechnic, Telecommunications and Informatics Laboratory (LETIA), University of Abomey-Calavi, Abomey-Calavi, Benin \\ ${ }^{2}$ Electronic, Electrotechnic, Automatic, Telecommunications Laboratory (LEEAT), University of Douala, Douala, Cameroon \\ ${ }^{3}$ Polytechnic School of Abomey-Calavi (EPAC), University of Abomey-Calavi, Abomey-Calavi, Benin \\ ${ }^{4}$ Laboratory of Thermophysic Characterization of Materials and Energy Mastering, University of Abomey-Calavi, Abomey-Calavi, Benin
}

Email address:

olouarou@yahoo.fr (Arouna O.), moukangueimano@gmail.com (Adolphe M. I.), moukangueimano@gmail.com (François-Xavier F.), olouarou@yahoo.fr (Mahamoud T.), akouemrichedans06@gmail.com (Akouèmaho R. D.), ramanou@yahoo.fr (Ramanou B.),

avianou@yahoo.fr (Antoine V.)

${ }^{*}$ Corresponding author

\section{To cite this article:}

Arouna Oloulade, Adolphe Moukengue Imano, François-Xavier Fifatin, Mahamoud Tanimomon, Akouèmaho Richard Dansou, Ramanou Badarou, Antoine Vianou. Contribution to the Economic and Optimal Planning of Multi-GED and a FACTS in a Distribution Network by Genetics Algorithms. American Journal of Electrical Power and Energy Systems. Vol. 9, No. 2, 2020, pp. 26-40.

doi: $10.11648 /$ j.epes.20200902.11

Received: April 16, 2020; Accepted: May 3, 2020; Published: June 20, 2020

\begin{abstract}
The distribution networks are more and more heavily loaded due to economic growth, industrial development and housing. The operation of these networks under these conditions generates voltage instabilities and excessive power losses. The present work consisted in the optimal integration of multi-GED (Decentralized Energy Generators) (Photovoltaic (PV), Fuel Cell (FC or PAC) and Wind Generator (WG)) and FACTS (SVC) in a Medium Voltage distribution's departure of the Beninese Electrical Energy Company (SBEE), with a view to improve its technical performances. The diagnostic study of the Ouidah 122-nodes test network, before optimization, revealed that the active and reactive losses are $457.34588 \mathrm{~kW}$ and $625.41503 \mathrm{kVAr}$ respectively. This network has high voltage instability with a minimum voltage of 0.80455 p.u. and a minimum VSI of 0.41897 p.u. The optimization of the size and positioning of GED and FACTS was based on the Nondominated Sorting Genetic Algoritm II (NSGA II). After optimization with the NSGA II, a comparative study of the different combinations between the three GEDs and the SVC, made it possible to choose that of the placement of a $121 \mathrm{~kW}$ Wind Generator at node 75, a PV of $131 \mathrm{~kW}$ at node 51, a system of Fuel Cell (FC, PAC in french) of $700 \mathrm{~kW}$ at node 34, and an SVC of 2.126 MVAr at node 94 of the network. This positioning enabled a reduction of $65.11 \%$ in active losses and $65.12 \%$ in reactive losses. The voltage profile and the voltage stability are clearly improved, with a minimum voltage of 0.96993 p.u. and a minimum VSI of 0.88505 p.u. The initial investment for this project is seven hundred and seven million three hundred and fifty-two thousand three hundred and fifty-eight point seven CFA francs (707,352,358.7 CFA francs). The technical and economic evaluation shows that the payback period is approximately 4 years 6 months and 14 days. The relevant results obtained show that the method used is efficient and effective, and can be applied to other MV departures of the SBEE.
\end{abstract}

Keywords: GED, SVC, NSGA II, Optimun Position, Optimal Size

\section{Introduction}

The development and economic growth of any nation is hugely dependent on the availability and quality of the energy supplied. Thus, the managers of the electrical network find themselves in a contractual obligation to ensure the supply of electrical energy of sufficient quality and quantity to meet the 
balance of supply and demand and meet the requirements of regulators which regulate the energy sector in several countries They are then subject to compliance with the most decisive performance criteria (stability, continuity of service, economy). The constantly increasing charges, due to the demographic and industrial growth of the countries, generate various disturbances on the electrical network, in particular the losses of power, the drops in voltage and excessive Non Distributed Energies (END), recurrent triggers, dispersions of dangerous potentials resulting from the poor flow of atmospheric discharges to the ground.

Also, it is strong to note the incapacity of the conventional means of voltage regulation (load regulators, capacitors, phase shifting transformers, regulators of distribution transformers...) in distribution networks, to properly manage the flows of loads, improve the bar voltage profiles and increase the reliability of energy systems.

To remedy this, various effective approaches can be envisaged.

One of these solutions is the decentralization of production by Decentralized Energy Generators (GED). It makes it possible to reduce the lengths of the lines for transporting electrical energy, thereby reducing active and/or reactive losses on line. Among these GEDs, we can cite photovoltaic solar, wind generator, fuel cells, tidal power, biomass...

However, decentralizing production is not always enough to effectively solve all the problems on the electrical networks, especially in the event of high voltage instability. For example, the PVs fail to correct the voltage in the networks as much as the FACTS.

Taking advantage of the development of power electronics which has introduced new devices called FACTS (Flexible Alternative Current Transmission System), network managers are inserting them into the network to improve its performance. FACTS enable more efficient operation of electrical networks by acting directly and continuously on the basic parameters of the networks, notably the phase shift, voltage and impedance. Thus, they contribute to improving transit capacity, minimizing losses, improving voltage plans and increasing the operational flexibility of electrical networks. They act on the parameters both in stationary regime and in transient regime. Among these devices, the most used for networks with high voltage instability, are shunt devices including the SVC (Static Var Compensator).

However, it is not enough just to place GEDs or FACTSs [1]. Care must be taken to properly size them and find the most optimal position possible in the distribution network. For this fact, we often use optimization methods, especially meta-heuristics. The most commonly used are PSO (Particles Swarm Optimization), ACO (Ant Colony Optimization) and GA (Genetic Algorithm). GAs are the most popular because of their efficiency and ease of implementation. We mainly find SPEA (Strengh Pareto Evolutionary Algoritm) I and II, FastPGA (Fast Pareto Genetic Algorithm), NSGA (Nondominated Sorting Genetic Algorithm) I and II.

Thus, in the present work, it will be a question of developing a power flow algorithm, and of optimizing the size and the multi-GED positioning in the presence of the SVC in a distribution network, that of Ouidah. It will be a question of making a comparative study between the different possible combinations of three GEDs (Wind generator (WG), PV and PAC) with the SVC, to bring out the best. This study will be based not only on technical performance (reduction of energy losses, improvement of the voltage profile, etc.), but also on the environmental impact (reduction of gas emissions) and recovery of the energy saved. to ensure the profitability of the project. For this, we will use the genetic algorithm of nondominated sorting, the NSGA II, as an optimization tool.

\section{Literature Review}

The optimal size and positioning are two key factors in the integration of decentralized productions and FACTS into existing electrical systems, and have become, in recent years, real challenges and have been the subject of several studies. These studies, as diverse as they are, are generally based on technical criteria (reduction of power or energy losses, improvement of the voltage profile, indices of network stability and performance, reduction of energy not distributed, etc.), economic (reduction in investment cost, reduction in upkeep and maintenance costs, profitability of the GED and SVC placement project, etc.) and environmental (reduction of gas emissions, etc...) and use the multiple methods of analysis and optimization available.

One of the most used approaches for positioning and sizing GED is the analytical method. Thus, D. Q. Hung et al. presented a methodology for the integration of distributed (biomass) and non-dispatched (wind genrator) decentralized production units in renewable energy into electrical networks with a view to minimizing annual energy losses [2]. Analytical expressions are used to find the optimal size and power factor of the GED for each position in order to minimize power losses. These expressions are then adapted to place the GEDs for the minimization of the annual energy lost, taking into account the temporal variation of demand and production. The method has been tested on the IEEE network 69 nodes for various scenarios

Besides the analytical methods, there are several other approaches. Srinivas and Kale develop three positioning methods using respectively the PSO, the Modified Teaching Learning-Based Optimization algorithm (MTLBO) and the Jaya algorithm [3]. The goal is to reduce power losses and improve voltage stability. They use the VSI. The different algorithms were tested on the IEEE 33 network and the results compared to those obtained with the conventional analytical method.

ALO (Ant Lion Optimization) is also an optimization method used for the positioning of GEDs in the distribution network. This is the approach used by Reddy P. et al. for the optimal positioning of GED types 1,2 and 3. The approach is tested on IEEE 15, 33, 69 and 85 networks [4].

Based on the PSO, Athira et al. [5] improved the technical performance of the distribution network by the simultaneous positioning of PAC and PV.

The FAMPSO (Fuzzy Adaptive Modified Particle Swarm Optimization algorithm) was used to position a central heating station in a distribution network and tested on the 
IEEE 69 network by Farjah et al. [6]. The objective function used involves the reduction of energy losses, the reduction of gas emissions and the reduction of the voltage deviation.

Minh Quan et al. used BBO (Biogeography-Based Optimization) to position PV in the network. Power losses, THD (Total Harmonic Distortion) and IHD (Individual Harmonic Distortion) are optimized technical performance [7]. It is evaluated on the IEEE 33 and the IEEE 69. The comparisons made with the PSO, the ABC (Artificial Bee Colony algorithm) and the GA allowed to conclude that this approach is effective.

The placement problem of SVC also requires the use of optimization methods and has been the subject of various studies.

Majid et al. used NSGA II for optimal placement of SVC and TCSC in the 30-node IEEE network [8].

Walaa et al. use probabilistic approaches for optimal placement of the CVS. Several methods have been used and compared in the context of their work. These are NSGA II, MOPSO, PESA II and SPEA-2 [9]. The IEEE 33 and IEEE 69 networks are the test networks.

Mohamad Zamani et al. placed SVC in a network using the Symbiotic Organism Search (SOS) algorithm [10]. The voltage deviation index was used to determine the position of the SVC. Then, the SOS enabled the size of the SVC to be optimized.

Studies have been carried out for the simultaneous positioning of GED and SVC.

Thus, Thishay and Balamurugan have developed a method based on VSI for the positioning and dimensioning of SVC and GED in a distribution network [11]. This approach has been tested on the IEEE network of 33 nodes

Rath and Ghatak addressed the problem of positioning GED and SVC using PSO [12]. This positioning was performed by a combination of the PSO with the Rapid Voltage Stability Index (FVSI) and the Line Stability Index (LQP). The contribution of GED and or SVC was assessed by the voltage profile increase index (VPII), the line loss reduction indices (ILP and ILQ) and the net present value of the installation. This approach has been tested on the IEEE 30 node and IEEE 12 node networks. Tests have shown that GED has a considerable contribution in reducing losses compared to SVC.

Another very effective method of studying the integration of GED into existing networks is the direct consideration of the study of the profitability of the project in formulating the positioning problem. This consistent approach makes it possible to satisfy both the technical performance of the network, but also to ensure the profit margin for the network manager, while respecting the environment. In this context, Ali and Yang are based on the stochastic method of network planning, ADNP (Active Distribution Network Planning) for multi-GED positioning (Wind turbine $+\mathrm{PV}+$ Storage battery) [13]. The objectives formulated are the minimization of power losses, the rational exploitation of GEDs for the satisfaction of demand, and the maximization of NPV (Net Present Value). The approach is evaluated on the IEEE network of 123 nodes and on a real network of 53 nodes.

A similar approach was also used by Rodriguez-Gallegos et al. for the positioning of PV and Storage Batteries in an
Indonesian distribution network [14].

\section{Calculation of the Electrical Condition of a Radial Distribution Network}

The calculation of the electrical state of an electrical network involves the analysis of its power flow. Also called "load distribution" or "load flow", it is a basic tool and necessary for any electrical system, and having for objective the determination of the various electrical variables (current in the lines, the voltage profile, power transits, line losses, etc.) at a given time, for a given state of consumption and production. The general methods, namely Newton-Raphson, Gauss-Seidel, Scott and FDLF (Fast Decoupled Load Flow) [15], converge well and are suitable for transport networks. However, they remain ineffective for the analysis of distribution networks [16]. For these radial networks, the suitable methods are those based on the Backward and Forward Sweep (BFS) or double scanning, due to the low $\mathrm{X} / \mathrm{R}$ ratio of the distribution networks, the radial structure and the unbalanced load distribution [17].

The BFS variant used in this work is that of current and voltage injection, based on the BIBC (Bus Injection to Branche Current) and BCBV (Branche Current to Bus Voltage) matrix.

\subsection{Mathematical Model of Network Elements}

Assuming the linear network with balanced steady-state operation [18], the study of the network can be carried out using an equivalent single-phase network presented at Figure 1.

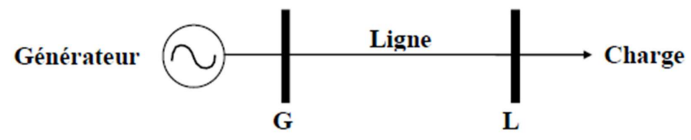

Figure 1. Single line diagram of a single power transmission line

In this model, the generators are considered as variable voltage sources in series with an induction reactance (Figure 2 (a)). In the p.u. system, this induction reactance is equal to the unit, under normal conditions.

The branches are represented by a resistor in series with an inductive reactance (Figure $2(\mathrm{~b})$ ). The line impedance is then calculated by:

$$
\overline{Z_{i}}=R_{i}+j \cdot X_{i}
$$

As for the loads, they are seen as consumers of active power $P_{i}$ and reactive power $Q_{i}$ (Figure $2(\mathrm{c})$ ). The apparent power is then:

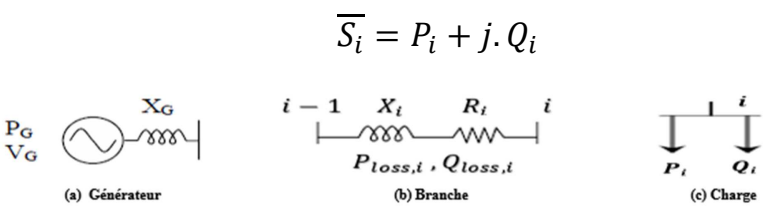

Figure 2. Single-line diagram. 


\subsection{Formation of BIBC and BCBV Matrices}

The formulation of these two matrices is essentially based on the topological data of the network. These are in particular the number of nodes $n$, the number of branches $b$, the base voltage $V_{B}$, the base power $S_{B}$, as well as the powers of the charges at the nodes and the characteristics of the lines.

The BIBC matrix:

The BIBC matrix establishes the link between the current injections of the load nodes and the currents of the different lines

The approach allowing the construction of this matrix is described by the Algorithm 1.

Algorithm 1 Formation of the BIBC matrix

Step 1: Create the $b \times a$ dimension matrix and initialize it to zero. Each column represents a node, except the source node.

Step 2: Set the first item to "1", $B I B C(1,1)=1$.

Step 3: Either the branch $i, i \neq 1$, between the nodes $i-1$ and $i$.

a) Copy column $i-1$ from the BIBC matrix into column $i$.

b) Set the $i^{\text {th }}$ element of the line $i$ to +1 .

Step 4: Repeat the previous steps for all branches of the network.

The matrix obtained is an upper triangular matrix, containing only 0 and 1 .

The BCBV matrix:

This matrix is the ratio between the branch currents and the nodal voltages. The process of its formation is described by the Algorithm 2.

Algorithm 2 Formation of the BCBV matrix

Step 1: Create the matrix of dimension $a \times b$ and initialize it to zero. Each line represents a node, except the source node.

Step 2: Set the first item to " $Z_{1}$ ", $B C B V(1,1)=Z_{1}$.

Step 3: Either the branch $i, i \neq 1$, between the nodes $i-1$ and $i$.

a) Copy line $i-1$ from the BCBV matrix into line $i$.

b) Set the $i^{\text {th }}$ element of the line $i$ to $Z_{i}$.

Step 4: Repeat the previous steps for all branches of the network.

The matrix obtained is a lower triangular matrix, containing only 0 and $Z_{i}$.

\subsection{Algorithm of BIBC/BCBV Method}

The power flow method developed in this work finds its simplicity in the exploitation of Kirchhoff's laws. It is based on the structure of radial electrical distribution networks. It uses the BIBC and BCBV matrices, while implementing the principle of double scanning.

The stages of power flow by the method based on the matrices BIBC and BCBV, are described by the Algorithm 3 .

Algorithm 3 Power flow by the BIBC/BCBV method

Step 1:

1) Read network data:
a) Number $n$ of nodes;
b) Number $b$ of branches;
c) Characteristics of the lines;
d) Information on the charges at each node.

2) Read tolerance $\varepsilon(\varepsilon=0.00001)$.

3) Read base voltage and power.

Step 2:

1) Formation of BIBC and BCBV matrices.

2) Initialization of iterations, $k=1$.

Step 3: Backward Sweep.

1) Calculation of current injections at the different nodes as follows:

$$
\overline{I_{i}}=\left(\frac{s_{i}}{V_{i}}\right)^{*}
$$

2) Calculation of branch currents by:

$$
[J]=[B I B C] \cdot[I]
$$

Step 4: Forward Sweep.

1) Calculation of the voltage drop by:

$$
[\Delta V]=\left[V_{0}-V_{i}\right]=[B C B V] .[J]
$$

2) Calculation of new nodal voltages, $\left[V^{(k+1)}\right]$ by:

$$
[V]=\left[V_{0}\right]-[\Delta V]
$$

Step 5: Assessment of the stopping criterion.

Calculate the maximum difference between the values of nodal voltages of two consecutive iterations:

$$
D_{\max }=\max \left(\left[V^{(k+1)}\right]-\left[V^{(k)}\right]\right)
$$

1) Check if the maximum deviation is below the tolerance $\left(D_{\max }<\varepsilon\right)$.

2) If yes, go to Step 6 .

3) If not:

a) go to the next iteration, $k=k+1$.

b) back to Step 3 .

Step 6: Calculate the VSI at each node, by:

$$
\begin{aligned}
V S I_{i+1}= & \left|V_{i}\right|^{4}-4 *\left(P_{i+1} \cdot X_{i+1}-Q_{i+1} \cdot R_{i+1}\right)^{2}-4 * \\
& \left(P_{i+1} \cdot R_{i+1}+Q_{i+1} \cdot X_{i+1}\right) *\left|V_{i}\right|^{4}
\end{aligned}
$$

Step 7: Perform the power balance.

1) Total active loss:

$$
P_{\text {T.loss }}=\sum_{i=1}^{b} P_{\text {loss }, i}=\sum_{i=1}^{b} R_{i} *\left|J_{i}\right|^{2}
$$

2) Total reactive loss:

$$
Q_{T . l o s s}=\sum_{i=1}^{b} Q_{\text {loss }, i}=\sum_{i=1}^{b} X_{i} *\left|J_{i}\right|^{2}
$$

3) Powers of the source node:

$$
\begin{gathered}
P_{\text {slack }}=P_{d}+P_{T . \text { loss }}=\sum_{i=1}^{a} P_{i}+P_{T . l o s s} \\
Q_{\text {slack }}=Q_{d}+Q_{T . \text { loss }}=\sum_{i=1}^{a} Q_{i}+Q_{T . \text { loss }}
\end{gathered}
$$

Step 8: Show power flow solutions.

\subsection{Power Flow Results}

\subsubsection{IEEE 69 Nodes Network}

The validation of the developed power flow method is done on the IEEE 69 standard network, the structure of 
which is presented at Figure 3.

This network has a voltage level of $12.66 \mathrm{kV}$ and its data is taken from [19].

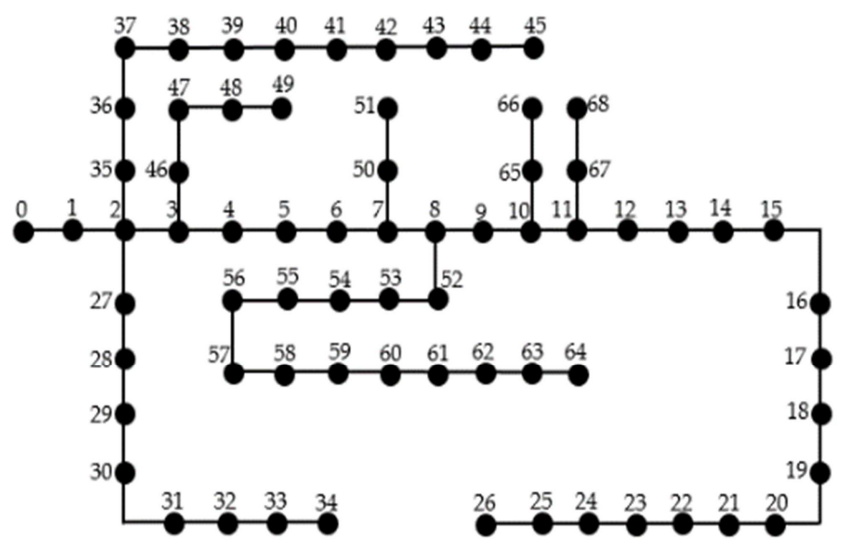

Figure 3. Diagram of the 69-node IEEE network

This network is simulated with the algorithm developed in MATLAB and the results obtained have been compared to those of Pedanna and Rama [20].

The voltage profile is shown at Figure 4.

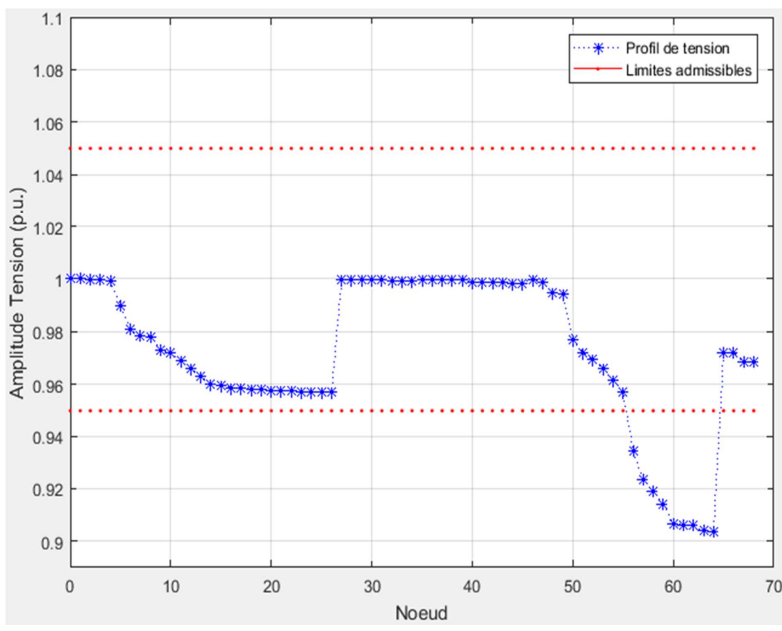

Figure 4. Voltage profile of the IEEE network 69 nodes.

The summary of the comparison is entered in the Table 1 .

Analysis of the results in Table 1 shows that the voltages obtained by the method developed are almost identical to those of the reference. Also, the deviations obtained are within the admissible ranges.

Table 1. Comparison of test results on the IEEE 69 nodes.

\begin{tabular}{llll}
\hline Parameters & Sophisticated method & Reference & Relative deviation (\%) \\
\hline Number of unstable nodes & 9 & 9 & 0 \\
Minimum voltage & 0.90338 p.u. (64) & 0.90930 p.u. (64) & 0.65 \\
VSI & 0.66594 p.u. (65) & - & - \\
Total active loss $(\mathrm{kW})$ & 238.6699 & 224.8799 & 6.13 \\
Total reactive loss (kVAr) & 106.9868 & 102.1091 & 4.77 \\
\hline
\end{tabular}

In view of these results, the current and voltage injection algorithm, based on the BIBC and BCBV matrices, developed in MATLAB, can be validated and applied to real networks.

\subsubsection{Ouidah MV Distribution Network}

The HVA departures of Ouidah are located in the commune of Ouidah. This network originates at the 161 $\mathrm{kV} / 20 \mathrm{kV}$ Avakpa transformer station located in the DRA. The Avakpa transformer station supplies two departures (Ouidah and Allada) and takes its source on the L225-161 kV line from Maria-Gléta and Momé Hagou. This network has 122 nodes, with a radial structure presented to The HTA departure from Ouidah is located in the commune of Ouidah. This network originates at the $161 \mathrm{kV} / 20 \mathrm{kV}$ Avakpa transformer station located in the DRA. The Avakpa transformer station supplies two departures (Ouidah and Allada) and takes its source on the L225-161 kV line from Maria-Gléta and Momé Hagou. This network has 122 nodes, with a radial structure presented at Figure 5.

The simulation of this SBEE network with the elaborate power flow method made it possible to obtain the voltage and VSI profiles presented at the Figures 6 and 7.

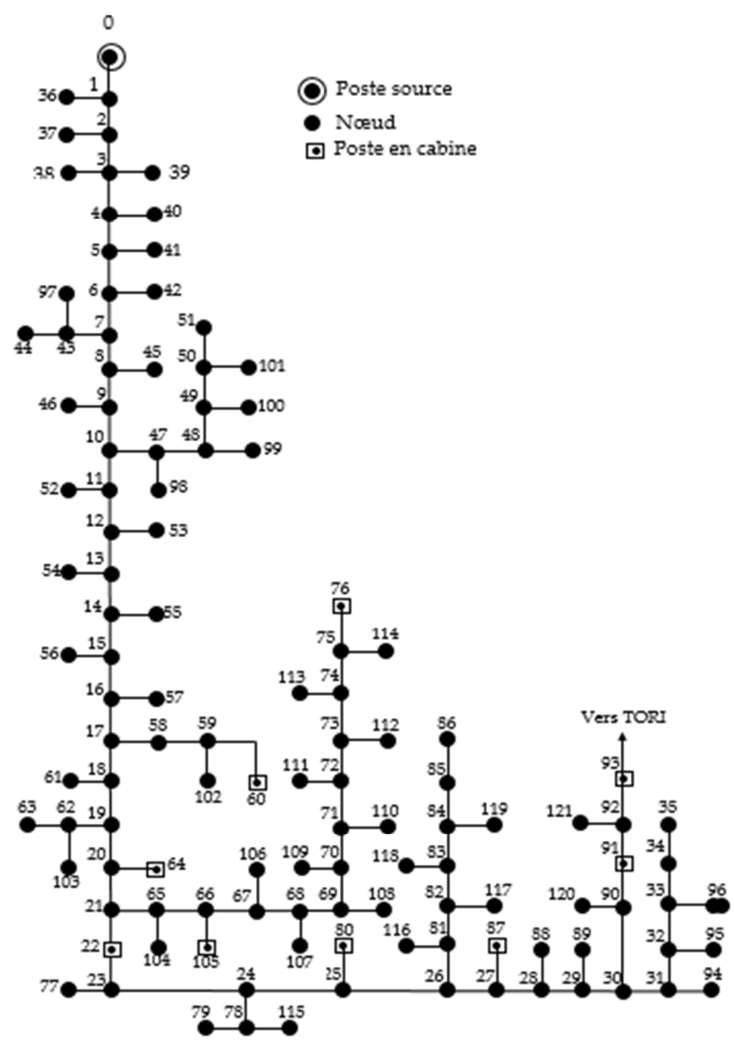

Figure 5. Ouidah network architecture. 


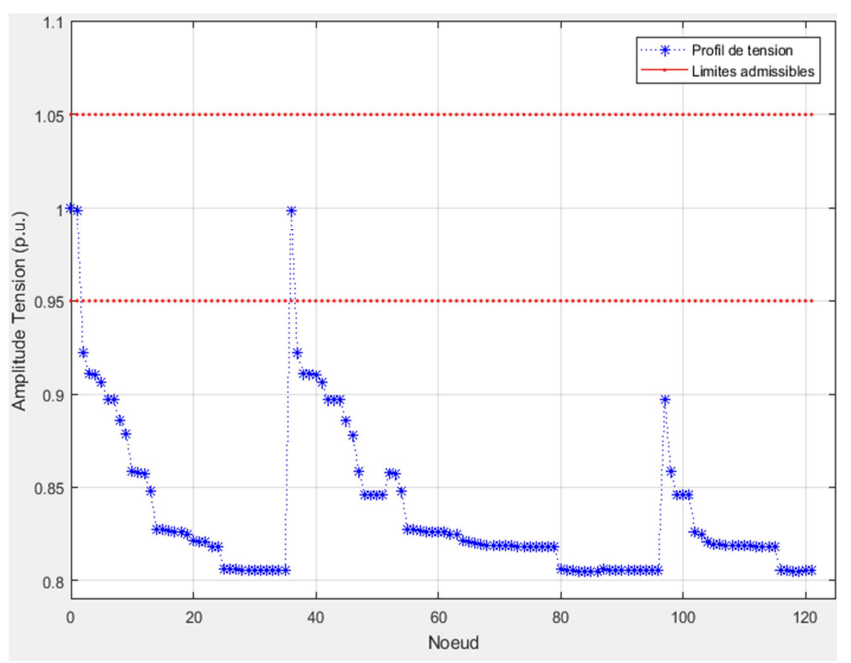

Figure 6. Ouidah network voltage profile.

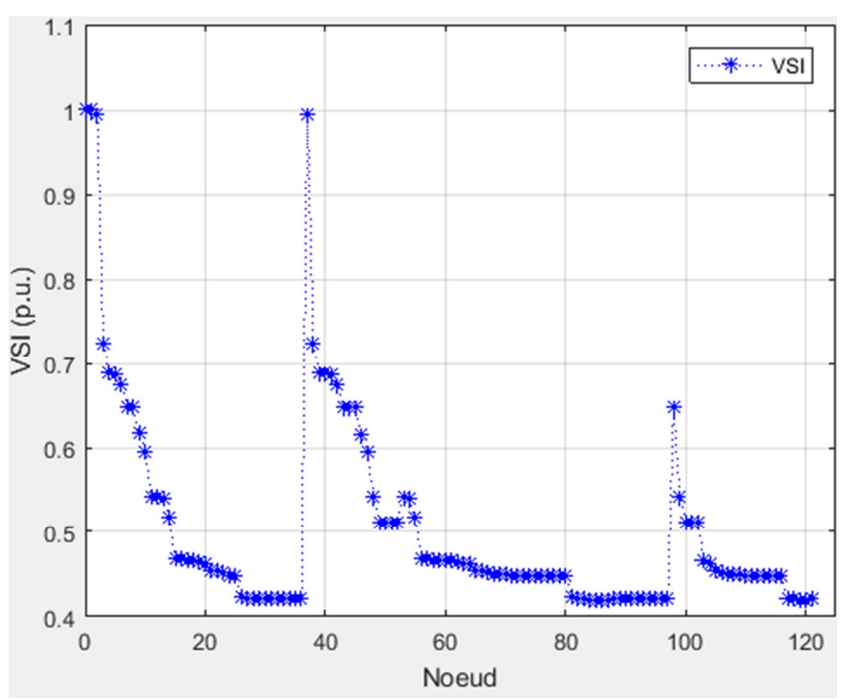

Figure 7. Ouidah network VSI profile.

From the analysis of these results, it appears that out of the 122 nodes of the network, only three (03) have amplitudes conforming to the NF 15160 and IEEE Standard 1860-2014 standards which stipulate that the nodal voltages must be in the proportions of $\pm 5 \%$ of the nominal value, i.e. 0.95 pu at 1.05 p.u., so that the receivers are properly powered, so this network has 119 unstable nodes, with a minimum voltage of 0.80455 p.u. at node 86 . The minimum VSI is then 0.41897 p.u. at node 87 .

In terms of losses, the power losses are $457.34588 \mathrm{~kW}$ (active losses) and 625.41503 kVAr (reactive losses). These losses represent respectively a rate of $13.45 \%$ of the total active power generated and $30.21 \%$ of the total reactive power generated. These rates do not comply with the tolerance for allowed power losses. Indeed, for distribution networks, power losses must be between 3\% and 5\% [21].

From various analyzes, it appears that the network of Ouidah is sinister, with excessive losses and a high instability in voltage.

\section{Formulation of the Problem of Size and Positioning of Multi-GED and SVC}

\subsection{GED Modeling}

A Decentralized Energy Generator (GED) is any energy source connected to the transport, distribution or distribution network and which is part of unconventional (wind, solar photovoltaic, fuel cell, etc.) or conventional energies. small power, power less than $200 \mathrm{MW}$ (gas micro-turbines, cogeneration, means of energy storage among others), outside large power plants. Their main advantages are: their short installation time (up to less than six months), their low investment and maintenance cost, the reduction of line losses, the improvement of the voltage profile, the reduction of toxic gas emissions and increased energy efficiency and network reliability.

As part of our study, we opted for Type 1 GEDs (capable of providing active power only) and Type 3 (capable of providing active power and reactive power). For Type 1, we take the case of photovoltaic solar (due to the high solar potential available to Benin, with an average sunshine of 3.9 $\mathrm{kWh} / \mathrm{m}^{3}$ [22]) and that of fuel cells. Regarding Type 3, it will be the variable speed wind turbine, in particular that based on MADA (Asynchronous Dual Power Machine), because of the coastal edge available to Ouidah and the wind speed between 4 and $6 \mathrm{~m} / \mathrm{s}$.

The choice of GED type 1 is made because of their ability to provide active power. The latter is necessary in our study to influence the power transit and thereby reduce losses. As for GED type 3, it is not only the supply of active power but also its ability to provide reactive power when needed.

GEDs are integrated into electrical networks to provide or absorb active or reactive power or both. Thus, whatever the type of GED, they are considered as sources of active and/or reactive power (positive or negative, depending on the type).

A GED placed in node $i$ is then represented as shown at Fihure 8.

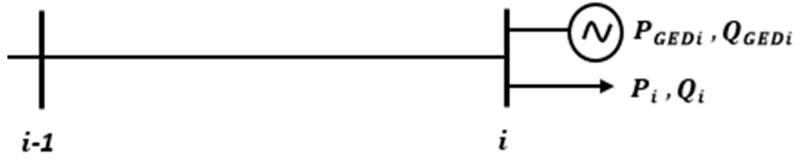

Figure 8. Connection of a GED to node $i$.

With this integration, the power injection at the node changes. In the presence of the GED, the new active and reactive powers consumed at this node are then:

$$
\left\{\begin{array}{l}
P_{i, \text { new }}=P_{i}-P_{G E D i} \\
Q_{i, \text { new }}=Q_{i}-Q_{G E D i}
\end{array}\right.
$$

with $\left\{\begin{array}{c}P_{i}, Q_{i}: \text { the initial active and reactive powers of the load } i \\ P_{G E D i}, Q_{G E D i} \text { the active and reactive powers of the GED } \\ P_{i, n e w}, Q_{i, n e w}: \text { the new powers consumed at the node } i\end{array}\right.$

Note that there is a relationship of dependence between the 
active and reactive powers of the GED. Indeed, the reactive power is given by:

$$
\left\{\begin{array}{c}
Q_{G E D i}=a * P_{G E D i} \\
a= \pm \tan \left(\arccos \left(P F_{G E D}\right)\right)
\end{array}\right.
$$

\subsubsection{PV Modeling}

PV being a GED of Type 1, it is modeled like a source (injection) of active power $P_{P V}$ only. When it is placed in a node $i$, the power in this node becomes:

$$
P_{i, \text { new }}=P_{i}-P_{P V}
$$

The reactive power of the node does not undergo any modification because $P_{P V}=0$.

Depending on the power of the PV to be installed, the investment cost (purchase and installation) is determined as follows:

$$
C_{\text {inst }, P V}=K_{\text {inst }, P V} \cdot P_{P V} \text { with } K_{\text {inst }, P V} \text { in } \$ / k W
$$

As for the annual cost of maintenance of the photovoltaic power plant, it is assessed as follows:

$$
C_{m, P V}=K_{m, P V} \cdot P_{P V} \text { with } K_{m, P V} \text { in } \$ / k W / y r
$$

\subsubsection{Wind Generator Model}

The Wind Generator used in this work is based on a MADA. It is therefore a GED of Type 3. Therefore, it is modeled as a source (injection) of active powers $P_{W G}$ and reactive $Q_{W G}$. When placed in a node $\mathrm{i}$, the powers in this node become:

$$
\left\{\begin{array}{l}
P_{i, \text { new }}=P_{i}-P_{W G} \\
Q_{i, \text { new }}=Q_{i}-Q_{W G}
\end{array}\right.
$$

The cost necessary for the installation of this wind power plant is given by:

$$
C_{\text {inst }, W G}=K_{\text {inst }, W G} \cdot P_{W G} \text { with } K_{\text {inst }, W G} \text { in } \$ / k W
$$

As for the annual maintenance cost of a wind power plant, it is assessed as follows:

$$
C_{m, W G}=K_{m, W G} \cdot P_{W G} \text { with } K_{m, W G} \text { in } \$ / k W / y r
$$

\subsubsection{Fuel Cell (FC or PAC) Modeling}

PACs are active power $P_{P A C}$ sources only. Placed in a node $\mathrm{i}$, the active power injection in the latter becomes:

$$
P_{i, \text { new }}=P_{i}-P_{P A C}
$$

The necessary investment is:

$$
\begin{gathered}
C_{\text {inst }, P A C}=K_{\text {inst }, P A C} \cdot T_{v} \cdot \frac{P_{P A C}}{\eta} \\
K_{\text {inst }, P A C} \text { in } \$ / k W h \\
\eta \begin{array}{c}
k \text { ith }\{\text { the yield } \\
T_{v}: \text { the annual operating time in hours } \\
\eta \text { the }
\end{array}
\end{gathered}
$$

The efficiency is calculated according to the ratio between the power of the FC and the maximum power. We define:

$$
P L R=\frac{P_{P A C}}{P_{\max , P A C}}
$$

a) if $P L R<0,05$ then $\eta=0,2716$

$$
\begin{aligned}
& \text { b) if } P L R \geq 0,05 \quad \text { then } \\
& \eta=0,9030 \cdot P L R^{5}-2,999 \cdot P L R^{4}+3,6503 \cdot P L R^{3}- \\
& 2,0740 . P L R^{2}+0,4623 \cdot P L R+0,3747
\end{aligned}
$$

The annual cost of upkeep and maintenance is assessed as follows:

$$
C_{m, P A C}=K_{m, P A C} \cdot T_{v} \text { with } K_{m, P A C} \text { in } \$ / h
$$

Fuel cells, during their operation, emit gases such as ammonia oxide $\mathrm{NO}_{x}$ and sulfur dioxide $\mathrm{SO}_{2}$. The total gas emission is given by:

$$
E_{P A C}=T_{v} \cdot P_{P A C} \cdot\left(e_{\mathrm{NO}_{x}}+e_{\mathrm{SO}_{2}}\right) \text { with } e_{\mathrm{NO}_{x}}, e_{\mathrm{SO}_{2}} \text { in } \mathrm{g} / \mathrm{kWh}
$$

\subsection{SVC Modeling}

The SVC (Static Var Compensator, i.e. static reactive power compensator), is a FACTS shunt device used in electrical networks to provide or absorb reactive power, in order to act on network parameters, in particular the voltage profile.

It is a group of parallel capacitors and inductors, with a fairly rapid control action, thanks to the switching of the thyristors or mechanically [23]. It is then generally represented by a combination of TSC-TCR (Thyristor Switched Capacitor - TCR).

The SVC is connected to the network via a coupling transformer ensuring the filtering of the harmonic currents resulting from the delay angle of the thyristors and from the resonance due to the presence of the capacitors.

It is considered as a variable parallel reactance (Figure 9), which is adjusted in response to the operating conditions of the electrical network in order to control its parameters, specifically the voltage.

Depending on the reactance (inductive or capacitive), the SVC is capable of drawing a capacitive or inductive current from the network, at the point of its coupling. Perfect control of this equivalent reactance makes it possible to regulate the voltage module at the SVC connection node, and therefore have a direct impact on the network voltage profile.

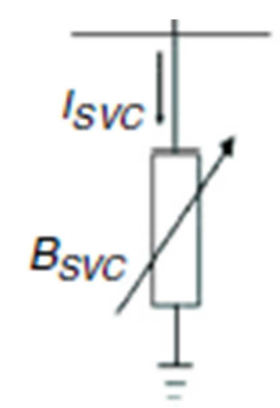

Figure 9. SVC variable shunt susceptance model.

Connected at a node $i$, the current that the SVC absorbs is given by: 


$$
I_{S V C}=j \cdot B_{S V C} \cdot V_{i}
$$

Depending on this current, the power of the installed SVC is determined, by:

$$
Q_{S V C}=j \cdot I_{S V C} \cdot V_{i}=-B_{S V C} \cdot V_{i}^{2}
$$

Thus, the power injected into this neoud is modified as follows:

$$
Q_{i, \text { new }}=Q_{i}-Q_{S V C}
$$

The investment necessary for the installation of such a system is given by [24]:

$$
C_{\text {inst }, S V C}=0,0003 \cdot Q_{S V C}^{2}-0,3051 \cdot Q_{S V C}+127,38
$$

$Q_{S V C}$ is in kVAr and $C_{\text {inst,SVC }}$ in dollars $\$$.

The cost of annual maintenance is given by:

$$
C_{m, S V C}=0,05 * C_{i n s t, S V C}
$$

\subsection{The Objective Functions}

\subsubsection{Technical Performance}

The almost permanent satisfaction of the demand and the respect of the margins of security and stability of the network, are the determining elements in term of performance of an electrical system. To contribute to this, the performances taken into account in this work concern the minimization of energy losses in lines and the minimization of deviation in expansion.

1) Lost energy:

The energy lost is the energy loss induced by power losses. Its reduction includes not only that of power losses, but also is related, in some way, to the reduction of undistributed energy. The annual active and reactive energies lost, are expressed by:

$$
\begin{gathered}
f_{1}=\text { lost active energy }=T_{v} \cdot P_{T . \text { loss }} \\
f_{2}=\text { lost reactive energy }=T_{v} \cdot Q_{T . \text { loss }}
\end{gathered}
$$

$w$ ith $T_{v}=T-T_{c}$ where $T_{c}$ is the annual cut - off time

2) Voltage deviation:

It expresses the relative difference between the nodal tension and the specific reference tension. The reduction of this factor will make it possible to bring back the nodal voltages $V_{i}$ within the limits of admissible voltages fixed by the standards in force. It is given by:

$$
f_{3}=\text { voltage deviation }=\max \left(\frac{\left|V_{0}\right|-\left|V_{i}\right|}{\left|V_{0}\right|}\right)
$$

In our work, technical performance is brought together in an aggregative function. This function groups together the active and reactive energies lost, and the voltage deviation. We have:

$$
F_{1}=0,4 * f_{1}+0,3 * f_{2}+0,3 * f_{3}
$$

\subsubsection{The Economic Criterion}

Taking this criterion into account makes it possible to ensure that the project is economically profitable and feasible. We will discuss here, minimizing the return on investment period (PRI) and maximizing the net present value (NPV).

1) The return on investment period:

It is a financial indicator that measures the time between investment and the cumulative recovery of invested capital. In other words, it is the time it takes for the cumulative revenue to balance the initial investment. PRI is determined with the following formula:

$$
f_{4}=P R I=\frac{C_{\text {inv.ini }}}{R_{\text {nette }}}
$$

With:

$$
\begin{gathered}
C_{\text {inv.ini }}=\text { Intitial investment }=C_{\text {inst }}+C_{\text {etude }} \\
C_{\text {inst }}=\text { installation cost } \\
C_{\text {etude }}=\text { study costs }=0,2 * C_{\text {inst }} \\
R_{\text {nette }}=\text { annual net revenue }=R_{\text {an }}-C_{m} \\
C_{m}=\text { annual maintenance costs } \\
R_{\text {an }}=\text { annual revenue }=K_{E} . E_{\text {save }} \\
K_{E}=\text { average cost of } k \text { Wh at } S B E E \\
E_{\text {save }}=\text { annual energy saved } E_{\text {save }} \\
=T_{v} *\left(P_{\text {T.loss avant }}-P_{T . l o s s}\right. \text { après }
\end{gathered}
$$

2) The net present value:

The net present value (NPV) of an investment is the difference between the net present gains of the investment (inflows minus outflows) and the starting bet. The investment will be profitable if this result is positive. It is calculated as follows:

$$
\begin{aligned}
V A N & =\frac{R_{a n}-C_{i n v}}{F_{c r f}} \\
f_{5} & =\frac{1}{V A N}
\end{aligned}
$$

With:

$$
\begin{gathered}
F_{c r f}=\text { return on investment factor }=\frac{d \cdot(1+d)^{t_{p}}}{(1+d)^{t_{p}-1}} \\
d=\text { discount rate } \\
t_{p}=\text { project life duration } \\
C_{\text {inv }}=\text { total investment cost } \\
C_{\text {inv }}=C_{\text {inv.ini }} \cdot F_{\text {crf }}+C_{m}+C_{r} \cdot F_{\text {ssf }}\left(d, t_{c}\right) \\
-C_{r} \cdot \frac{t_{r}}{t_{c}} \cdot F_{s f f}\left(d, t_{p}\right) \\
C_{r}=\text { cost of replacing equipment } \\
t_{c}=\text { lifetime of equipment } \\
t_{r}=\text { residual service life of equipment }
\end{gathered}
$$




$$
\begin{gathered}
F_{s f f}=\text { loss factor } \\
F_{s s f}\left(d, t_{c}\right)=\frac{d}{(1+d)^{t_{c}-1}} \\
F_{s s f}\left(d, t_{p}\right)=\frac{d}{(1+d)^{t_{p}}-1}
\end{gathered}
$$

\subsubsection{The Environmental Criterion}

This criterion consists in minimizing gas emissions. It is expressed by the function:

$$
f_{6}=E_{P A C}
$$

In this work, the economic (profitability) and environmental (reduction of gas emissions) aspects have been combined into a single objective function. This function is defined as follows:

$$
F_{2}=\left\{\begin{array}{c}
0,4 \cdot f_{4}+0,6 * f_{5}, \text { if } f_{6}=0 \\
0,3 * f_{4}+0,4 * f_{5}+0,3 * f_{6}, \text { if } f_{6} \neq 0
\end{array}\right.
$$

\subsection{Constraints}

The resolution of any optimization problem must be done under certain constraints. For the placement of GED and SVC, these constraints relate to the conditions of operation of the network and the standards in force.

\subsubsection{Equality Constraints}

The equality constraints concern the balance of the network, in the presence of GEDs and SVCs. We have:

$$
\begin{gathered}
P_{\text {slack }}+\sum_{i=1}^{n_{G E D}} P_{G E D i}=P_{d}+P_{T . l o s s} \\
Q_{\text {slack }}+\sum_{i=1}^{n_{G E D}} Q_{G E D i}+Q_{S V C}=Q_{d}+Q_{T . \text { loss }}
\end{gathered}
$$

\subsubsection{Inequality Constraints}

1) Constraints related to voltage:

This constraint makes it possible to maintain the nodal voltages in the range of admissible values. We have:

$$
V_{\min } \leq V_{i} \leq V_{\max }
$$

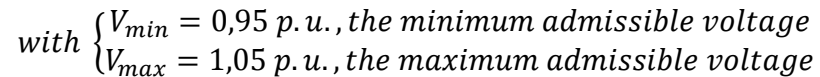

2) Constraint related to the capacity of GEDs:

The GEDs to be installed must have limited capacities, to ensure the balance of the system. We have:

$$
P_{G E D i}^{\min } \leq P_{G E D i} \leq P_{G E D i}^{\max }
$$

With $P_{G E D i}^{\min }$ et $P_{G E D i}^{\max }$, the minimum and maximum active powers of GED $i$.

3) Constraint related to the capacity of the SVC:

The SVC installed must have limited capacity. We have:

$$
Q_{S V C}^{\min } \leq Q_{S V C} \leq Q_{S V C}^{\max }
$$

With $\left\{\begin{array}{l}Q_{S V C}^{\min }=-V_{\min }^{2} \cdot B_{S V C}^{\max } \\ Q_{S V C}^{\max }=-V_{\text {max }}^{2} \cdot B_{S V C}^{\min }\end{array}\right.$

With $B_{S V C}^{\min }$ et $B_{S V C}^{\max }$, SVC's minimum and maximum shunt susceptances.

4) PV penetration rate:

The penetration rate is the ratio of the active power of the PV plant installed on the total demand of the network. This PV penetration rate in a distribution network must not exceed $30 \%$ of total demand in order not to disturb the network protection equipment. This constraint is formulated as follows:

$$
P_{P V} \leq 0.3 * P_{d}
$$

5) Constraint related to profitability:

A project is profitable when its net present value is positive. So, this constraint is formulated as follows:

$$
V A N>0
$$

\subsection{Adaptation of the NSGA II to the Problem of Size and Positioning Multi-GED in the Presence of the SVC}

The NSGA (Non-dominated Sorting Genetic Algorithm) II is an elitist Pareto genetic method, ie it uses the concept of Pareto dominance to perform a quick sorting, an overcrowding distance to ensure the divesity of the solutions in the same front and keeps Pareto-optimal solutions for reintroduction in new populations.

The optimization method based on the NSGA II is presented by algorithm 4 .

Algorithm 4 Multi-GED optimization in the presence of SVC, with NSGA II

Step 1: Read data.

a) Network data.

b) Parameters of NSGA-II, SVC and GED.

Step 2: Generate initial population $P_{0}=\left[x_{1}, x_{2}, \ldots, x_{N_{p o p}}\right]$ taking into account the information read in Step 1 then set the generation counter to zero $(t=0)$.

With $N_{\text {pop }}$ the number of individuals in the population and the $x_{i}$ are the decision variables (positions and sizes of the various GED and SVC).

Step 3: For each individual in the population $P_{t}$, run the power flow using the BIBC/BCBV algorithm and evaluate the objective functions.

Step 4: Check the constraints and add the penalty to the objective functions of the individuals who violated the constraints.

Step 5: Generate the $Q_{t}$ population of children from $P_{t}$ by applying genetic operators (crossing and mutation) to obtain the intermediate population $R_{t}=P_{t} \cup Q_{t}$ with size $2 * N_{\text {pop }}$.

Step 6: Classify the population $R_{t}$ by fronts (using the power flow).

Step: Select $N_{\text {pop }}$ individuals from the $2 * N_{\text {pop }}$ to form the population $P_{t+1}$.

Step 8: Increment the generation counter $(t=t+1)$ and repeat steps 3 to 7 until the total number of generations is reached.

Step: Take out the optimal solutions in the sense of Pareto and choose the best solution.

The parameters used are listed in Table 2. 
Table 2. NSGA II simulation parameters.

\begin{tabular}{ll}
\hline Parameters & Values \\
\hline Population size & 100 \\
Number of generations & 150 \\
Probability of crossing & 0,9 \\
Probability of mutation & 0,2 \\
Number of function-objective & 02 \\
Number of variables & 02 to 08 \\
Number of constraints & 04 to 06 \\
\hline
\end{tabular}

\section{Results and Discussions}

As part of this work, various combinations between GED (PV, PAC, Wind turbine) and SVC were studied.

\subsection{Optimization of GED Alone}

Here, we present the results from the optimization of sizes and positions of GED only in the network.

\subsubsection{Mono-GED Optimization: Wind Turbine Case}

After running the optimization algorithm based on the NSGA II, we obtained a population of solutions from which we chose the best. Thus, it will be necessary to install a 905 $\mathrm{kW}$ wind power plant at node 50 of the Ouidah network.

The integration of this plant reduces active and reactive losses by $34.39 \%$ and $38.14 \%$ respectively, bringing them to $300.06341 \mathrm{~kW}$ and $386.83065 \mathrm{kVAr}$. However, there are still 112 unstable nodes in the network (Figure 10). This project requires an initial investment of $1,173,174,344$ CFA francs and the return on investment will be made after 10 years, approximately 18 days.

The minimum voltage value is 0.85339 p.u. This voltage value is always lower than the minimum admissible value (0.95 p.u.). In addition, instability is also confirmed by the values of the VSI, the minimum value of which is 0.53037 .

Figure 10 presents the voltage profile in the presence of the wind turbine.

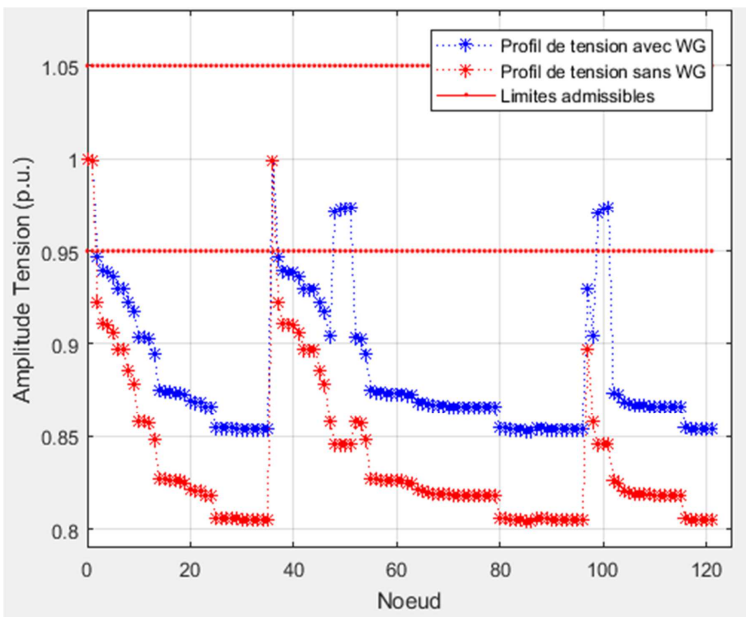

Figure 10. Voltage profile in the presence of the wind turbine.

There is certainly a slight improvement in stability, given this figure, but this improvement is not satisfactory.

The same observation was made for the single-GED positioning of PV and PAC separately.

\subsubsection{Multi-GED Optimization: Case of PV+PAC}

Execution of the optimization algorithm places a $100 \mathrm{~kW}$ PV central at node 121 and the $578 \mathrm{~kW}$ PAC at node 92.

This integration requires 432,229,782.6 CFA francs and ensures a reduction in active and reactive losses of $41.42 \%$ and $41.49 \%$ respectively. This reduction in losses is better than those obtained with each GED separately. However, the impact on the stress plane is still not interesting. The minimum value of the VSI is 0.51180 p.u. As for the tension, its minimum value is 0.94582 p.u. and is obtained at node 86 . The number of unstable nodes is 119 (Figure 11).

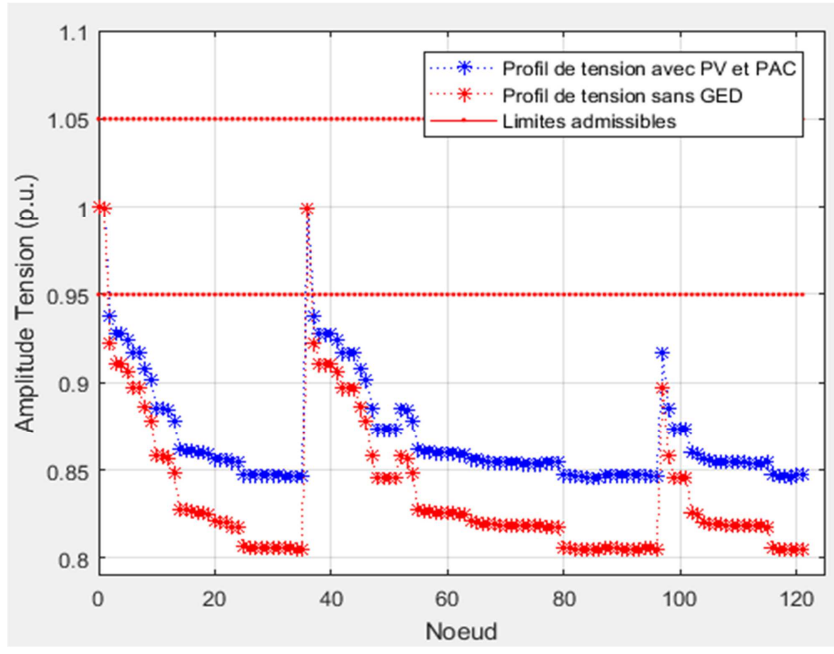

Figure 11. Voltage profile in the presence of $P V$ and PAC.

To remedy the problem of the stress plane, it is then necessary to find an effective solution. The most suitable solution is the installation of a FACTS shunt type device, here the SVC.

\subsection{Optimization of SVC Alone}

Optimizing the size and position of the SVC leads to the installation of a 3,523 MVAr SVC at node 72 of the Ouidah network.

The cost of installation is $1,656,338,617$ CFA francs, with a return on investment spread over approximately 5 months and 18 days.

With this integration, the voltage profile and the voltage stability are significantly improved. Indeed, it is noted that all the voltages are brought back within the range of admissible values. Thus, the minimum voltage value goes from 0.80455 p.u. to 0.97033 p.u., an increase of $20.60 \%$. Likewise, the minimum value of VSI goes from 0.41897 p.u. at 0.88651 p.u., an increase of $11.59 \%$. The tension profile is shown in Figure 12. 


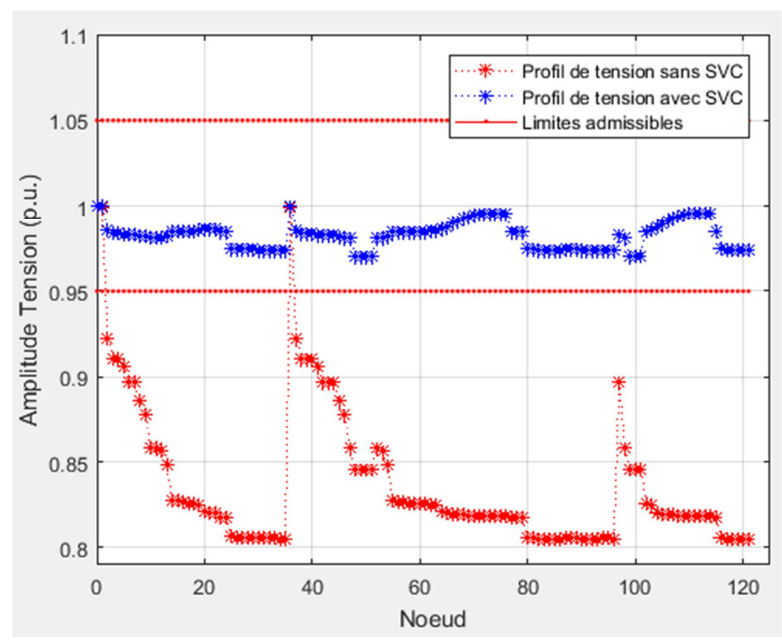

Figure 12. Voltage profile in the presence of SVC.

In addition, we note that the SVC does not really manage to influence the power transit in view of the reduction of losses. It only reduces active losses by $0.89 \%$ and reactive losses by $2.43 \%$.

\subsection{Multi-GED Optimization in the Presence of SVC}

In view of the previous results and analyzes, it is argued that taken separately, the GEDs and the SVC fail to resolve both the loss and voltage stability problems, while increasing the profit margin of the SBEE. Thus, the most likely solution is the combination of GED and SVC. It will then be question, here, to present the results from multi-GED optimizations in the presence of the SVC in the Ouidah network.

\subsubsection{Project 1: $P V+P A C+S V C$}

The optimization carried out allowed us to place a PV of $200 \mathrm{~kW}$, a PAC system of $282 \mathrm{~kW}$ and a SVC of 2,438 MVAr respectively at nodes 51,74 and 94 of the Ouidah network. This integration contributes to a $100 \%$ reduction in the number of unstable nodes, with a minimum tension of 0.96017 p.u. at node 76 (Table 3). There is also a significant improvement in terms of voltage stability, with a minimum VSI of 0.84997 p.u. The tension profile is shown in Figure 13.

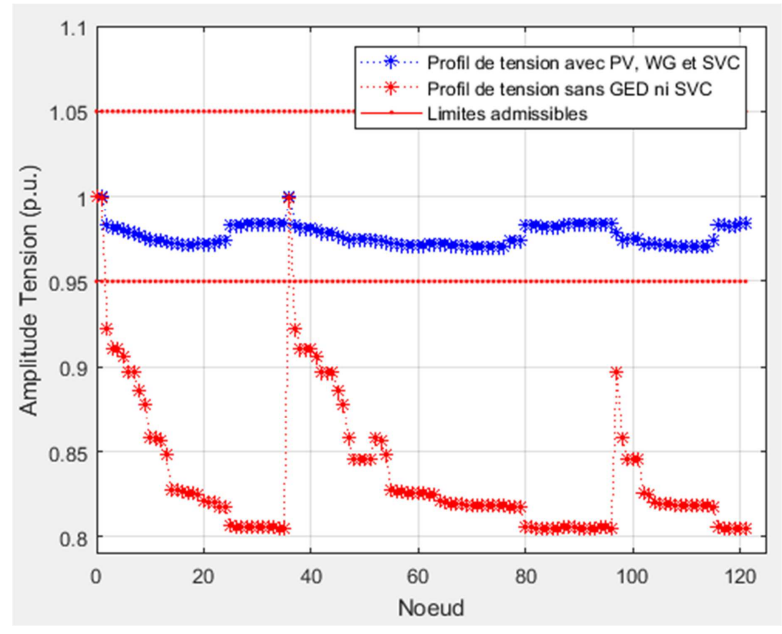

Figure 13. Voltage profile with $P V, P A C$ and $S V C$.

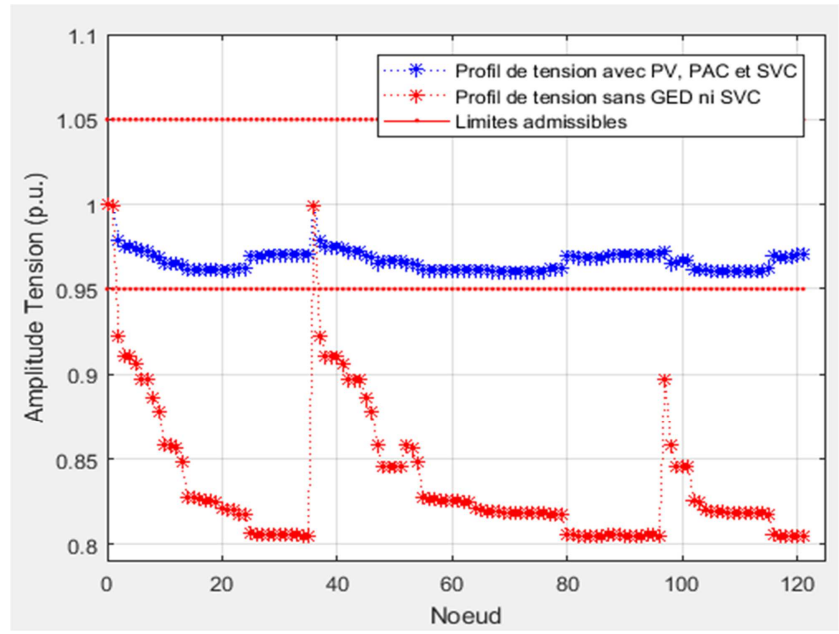

Figure 14. VSI profile with PV, PAC and SVC.

With these positioning, the active and reactive losses were reduced by $42.19 \%$ and $42.16 \%$, thus passing to 264.37152 $\mathrm{kW}$ and $361.73704 \mathrm{kVAr}$ respectively. This reduction increases the availability of electrical energy at the customer level and increases the profit margin of SBEE. This project will be installed at a cost of 439,350,784.9 CFA francs with a return on investment spread over 8 years 5 months and 27 days approximately.

\subsubsection{Project 2: $P V+$ Wind Turbine $+S V C$}

The execution of the optimization algorithm gives a central PV of $0.2 \mathrm{MW}$ at node 99, a wind power plant of $0.684 \mathrm{MW}$ at node 32 and an SVC of 1.955 MVAr at node 28. The results are presented in Table 3. The voltage and VSI profiles obtained are shown in Figures 15 and 16.

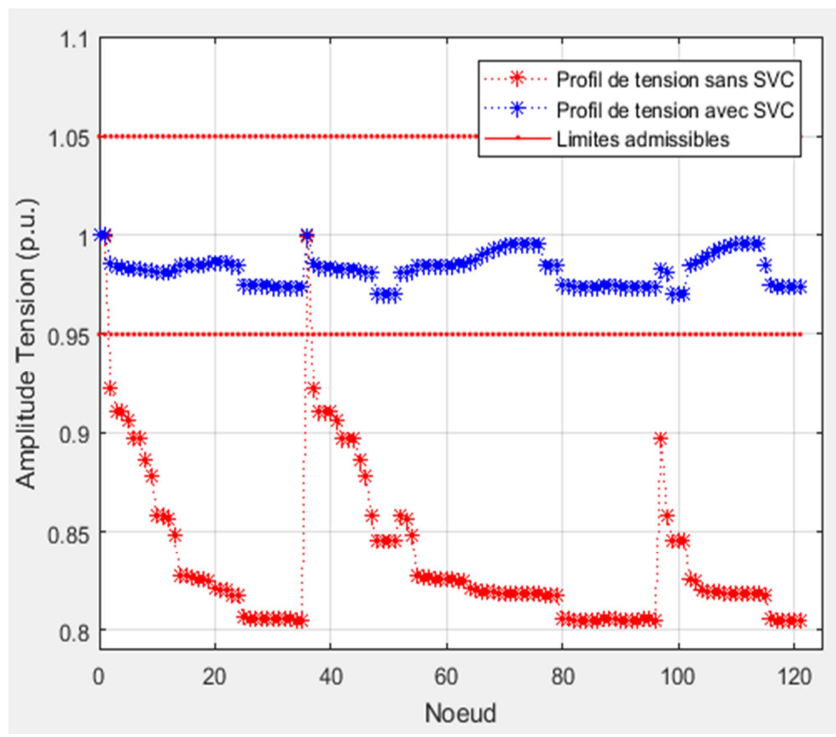

Figure 15. Voltage profile with $P V$, Wind turbine and $S V C$.

In these figures, there is a significant difference between the profiles before and after optimization. After optimization, all voltages are in the admissible value range. The minimum voltage value is then 0.97002 p.u. Voltage stability has also improved, with a minimum value of VSI increasing from 
0.41897 p.u. at 0.88366 p.u. There is also a reduction of $61.05 \%$ in active line losses. This reduction results in a net annual gain of $211,921,991.6$ CFA francs. This ensures a recovery of the funds invested after 5 years 7 months and 14 days approximately.

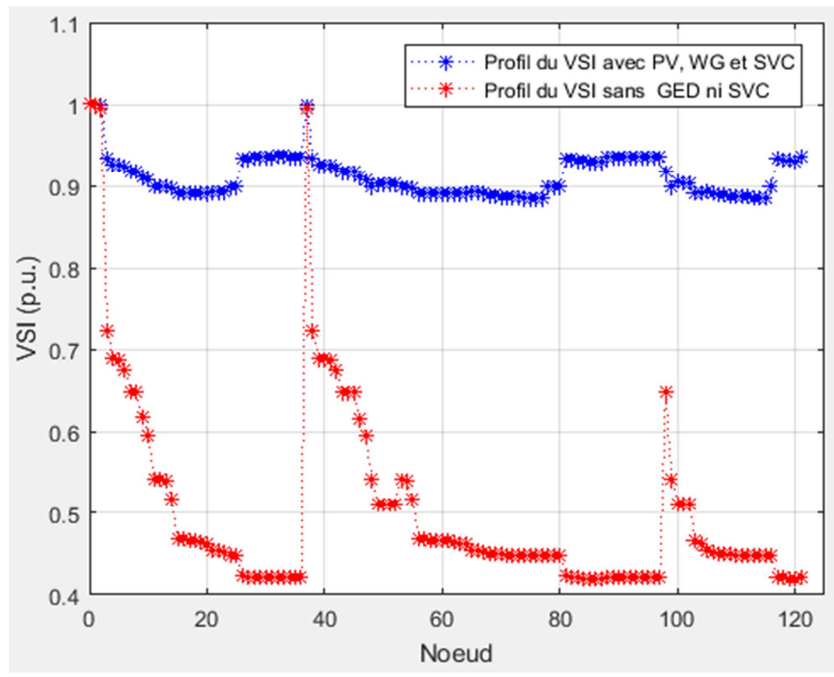

Figure 16. VSI profile with PV, Wind turbine and SVC.

\subsubsection{Project 3: $P A C+$ Wind Turbine $+S V C$}

For this combination, the solution chosen is that of the placement of a $200 \mathrm{~kW}$ Pac system at node 51, a $318 \mathrm{~kW}$ wind turbine at node 74 and a 2,217 MVAr SVC at node 93 of the Ouidah network (Table 3). The installation of these systems requires 505,551,789.2 CFA francs. The return on investment will be made after - years 2 months and 27 days approximately.

With the placement of these two GEDs and SVc, the state of the network is improved, with a $45.44 \%$ reduction in active losses. As for reactive losses, they go from 625.41503 kVAr to $341.40405 \mathrm{kVAr}$.

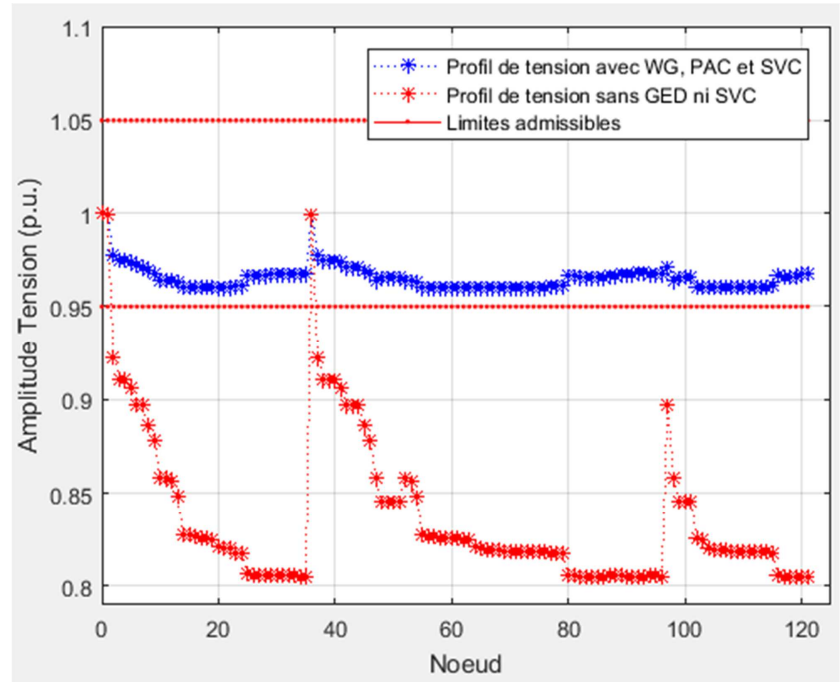

Figure 17. Voltage profile in the presence of PAC, wind turbine and SVC.

We note the absence of unstable nodes in the network. Indeed, after optimization, we note that all the voltages are in the range of admissible values. Thus, the minimum tension found is 0.95993 p.u. (Figure 17). This voltage stability is confirmed by the values of the VSI. The lowest VSI is then 0.84909 p.u. (Figure 18).

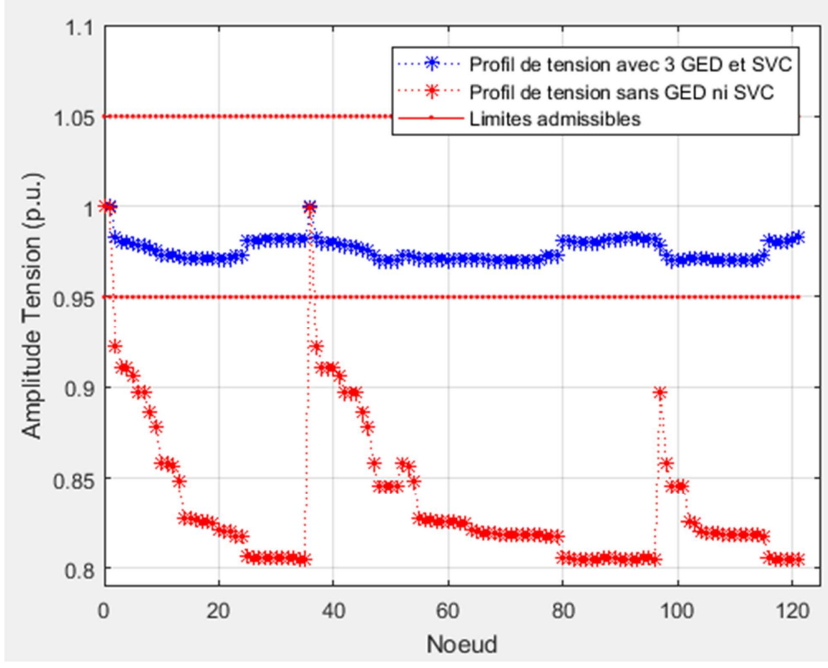

Figure 18. VSI profile in the presence of PAC, wind turbine and SVC.

\subsubsection{Project 4: $P V+P A C+$ Wind Turbine $+S V C$}

With regard to the positioning of the three GEDs and the SVC, the execution of the optimization algorithm places a central PV of $0.131 \mathrm{MW}$ at node 51, a wind turbine of 121 $\mathrm{kW}$ at node 75 , a Pac system of $700 \mathrm{~kW}$ at node 34 and a SVC of 2.126 MVAr at node 93.

This multi-GED integration in the presence of the SVC ensures a reduction of $65.12 \%$ in active losses and $65.11 \%$ in reactive losses. This reduction allows recovery of the funds invested after 4 years 6 months and 4 days approximately. From the voltage point of view, all the nodes are stable. The minimum voltage being 0.96993 p.u., or $19.3986 \mathrm{kV}$. The minimum VSI is then 0.88505 p.u. These profiles are shown in Figures 19 and 20.

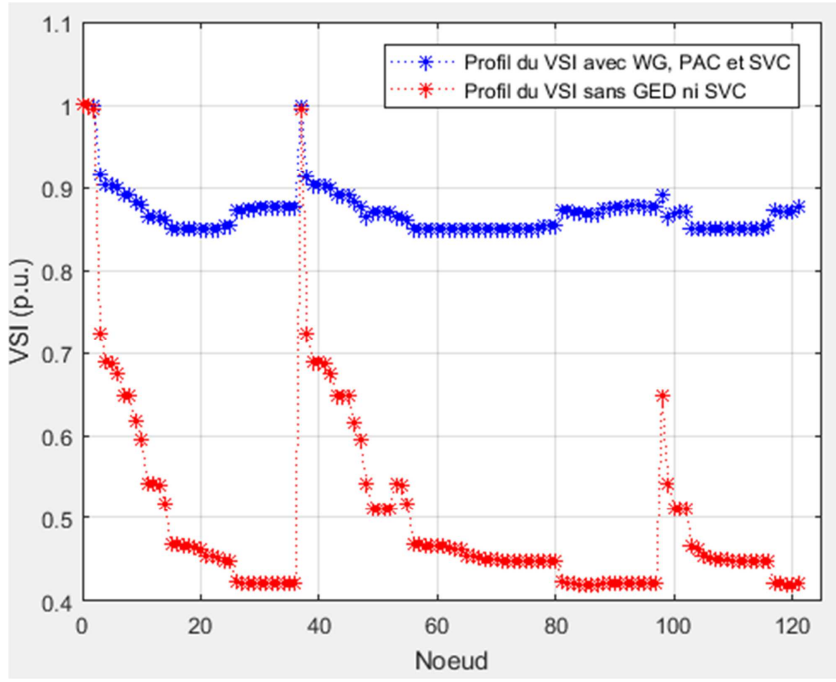

Figure 19. Voltage profile in the presence of $P V$, Fuel Cell, Wind turbine and $S V C$. 
Table 3. Summary of multi-GED optimizations in the presence of SVC.

\begin{tabular}{|c|c|c|c|c|c|}
\hline Parameters & Before optimization & $\begin{array}{l}\text { Project } 1 \\
\text { PV + PAC + SVC }\end{array}$ & $\begin{array}{l}\text { Project } 2 \\
\text { PV + WG + SVC }\end{array}$ & $\begin{array}{l}\text { Project } 3 \\
\text { PAC + WG + SVC }\end{array}$ & $\begin{array}{l}\text { Project } 4 \\
3 \text { GED + SVC } \\
\end{array}$ \\
\hline PV (kW) & - & $200 / 51$ & $200 / 99$ & - & $131 / 51$ \\
\hline PAC (kW) & - & $282 / 74$ & - & $200 / 51$ & $700 / 34$ \\
\hline WG (kW) & - & - & $684 / 32$ & $318 / 74$ & $121 / 75$ \\
\hline SVC (MVAr) & - & $2.438 / 94$ & $1.955 / 28$ & $2.217 / 93$ & $2.126 / 94$ \\
\hline$C_{\text {inst }}$ (F CFA) & - & $439,350,784.9$ & $1,168,039,710$ & $505,551,789.2$ & $693,482,704.6$ \\
\hline$C_{m}$ (F CFA/yr) & - & $103,522,086.3$ & $26,322,619.14$ & $105,909,924.4$ & $104,661,816.1$ \\
\hline$E_{P A C}(\mathrm{~g} / \mathrm{yr})$ & - & $92,328.209$ & - & 65,481 & $229,183.5$ \\
\hline$V_{\min }$ (p.u.) & $0.80455 / 86$ & $0.96017 / 76$ & $0.97002 / 76$ & $0.95993 / 109$ & $0.96993 / 76$ \\
\hline Unstable nodes & 119 & 0 & 0 & 0 & 0 \\
\hline$V S I_{\min }$ (р.u.) & $0.41897 / 87$ & $0.84997 / 77$ & $0.88536 / 77$ & $0.84909 / 110$ & $0.88505 / 77$ \\
\hline$P_{\text {T.loss }}(\mathrm{kW})$ & 457.34588 & 26437152 & 178.12310 & 249.49970 & 159.48801 \\
\hline Reduction of $P_{\text {T.loss }}$ & - & $42.19 \%$ & $61.05 \%$ & $45.44 \%$ & $65.12 \%$ \\
\hline$Q_{\text {T.loss }}(\mathrm{kVAr})$ & 625.41503 & 361.73704 & 243.41500 & 341.40405 & 218.16875 \\
\hline Reduction of $Q_{T . l o s s}$ & - & $42.16 \%$ & $61.05 \%$ & $45.41 \%$ & $65.11 \%$ \\
\hline$E_{\text {save }}(\mathrm{kWh} / \mathrm{yr})$ & - & 1446687.491 & 2205137.816 & 1744868.659 & 2411239.843 \\
\hline$R_{\text {nette }}(\mathrm{F} \mathrm{CFA} / \mathrm{yr})$ & - & 52779027.8 & 211921991.6 & 82606889.27 & 155850200.4 \\
\hline PRI (years) & - & 8.491 & 5.622 & 6.242 & 4.539 \\
\hline VAN (F CFA) & - & 63827318.57 & 1556350848 & 350326219.9 & 999126776.6 \\
\hline
\end{tabular}

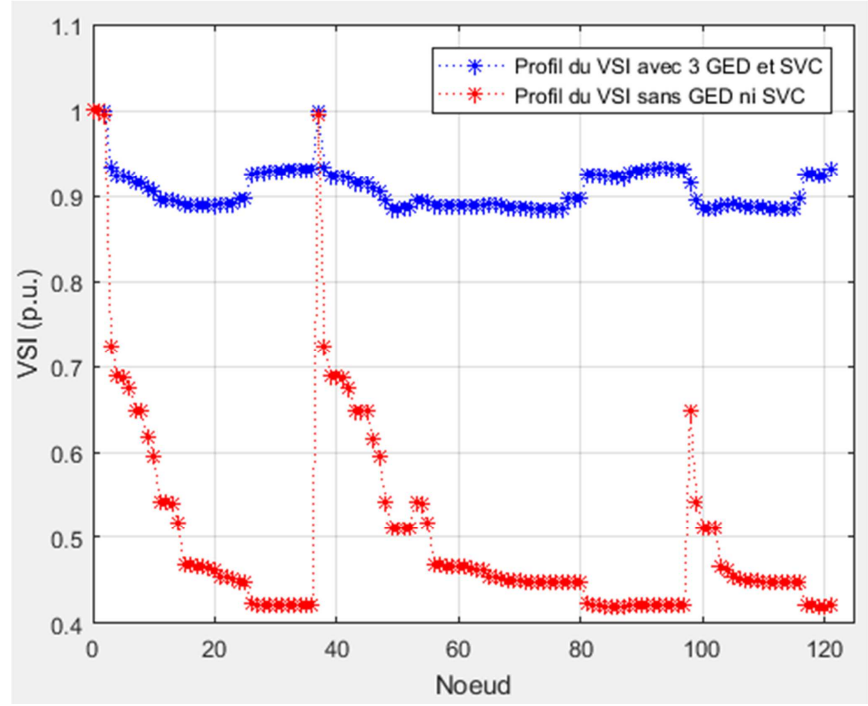

Figure 20. VSI profile in the presence of PV, Fuel Cell, Wind turbine and SVC.

\subsection{Choosing the Best Solution}

In view of the results presented in the previous section, we note that only multi-GED combinations in the presence of CVS manage to meet both technical, environmental and economic expectations. These combinations are all effective and profitable, a choice is necessary. In order to choose the best solution among these four combinations, a selection method is adopted.

We proceed to a classification. For this, six criteria are taken into account, namely: installation cost, return on investment period, NPV, minimum voltage, minimum VSI and active losses.

This classification will be done by weighting the parameters mentioned. Indeed, for each of these criteria, the solutions are classified according to their rank. The rank corresponds to the weight. This classification is done as follows:
1) for active losses, the first row is reserved for the solution giving less power losses, that is to say that offering a good reduction in active losses;

2) for the other five criteria, the first row is reserved for the solution with the highest value.

Then, depending on the total weight of each combination, we assign a rank for the classification. Thus, the solution that best adapts is the one with the lowest weight.

The results of this classification are presented in Table 4 .

Table 4. Ranking of the best solutions.

\begin{tabular}{lllll}
\hline Criterion & Project 1 & Project 2 & Project 3 & Project 4 \\
\hline$C_{\text {inst }}$ & 1 & 4 & 2 & 3 \\
PRI & 4 & 2 & 3 & 1 \\
VAN & 4 & 1 & 3 & 2 \\
$V_{\min }$ & 3 & 1 & 4 & 2 \\
$V S I_{\text {min }}$ & 3 & 1 & 4 & 2 \\
$P_{\text {T.loss }}$ & 4 & 2 & 3 & 1 \\
Poids total & 19 & 11 & 19 & 11 \\
\hline
\end{tabular}

At the end of this classification, we obtain two better solutions instead of one. These two solutions have the same weight (11). These are the PV + Wind turbine $+\mathrm{SVC}$ and PV + PAC + Wind turbine + SVC combinations.

To get the best out of it, we base ourselves on the installation cost and the active losses. On this basis, we note that the last combination ( $\mathrm{PV}+\mathrm{PAC}+$ Wind turbine $+\mathrm{SVC})$ is better, because it is less expensive and with a high reduction rate of active losses.

Thus, at the end of this work, the suitable solution for improving the technical performance of the Ouidah network and increasing the profit margin of the SBEE is the integration of three GEDs (PV, PAC and wind turbine) and an SVC. These are the positioning of a $121 \mathrm{~kW}$ wind turbine, a $131 \mathrm{~kW}$ photovoltaic power plant, a $700 \mathrm{~kW}$ PAC system and a SVC of 2.126 MVAr, respectively at nodes 75, 51, 34 and 94 of the Ouidah MV network. This project requires an initial investment of 707,352,358.7 CFA francs. 
This investment will be recovered after 4 years 6 months and 14 days approximately, thanks to a net annual income of $155,850,200.4$ CFA francs.

\section{Conclusion}

In this work, the proposed power flow method was tested on a standard 69 node network and on a real 122 node network of the SBEE. This method confirmed the state of the Ouidah distribution network, with excessive losses and high voltage insatability. To remedy this, a method for optimizing sizes and multi-GED positioning in the presence of SVC, based on the NSGA II, was proposed. With these methods, various combinations were studied and the application of a selection by weighting made it possible to choose the optimal solution among the best. From the results obtained, it appears that the optimization of sizes and multi-GED and SVC positions, with direct consideration of economic profitability, in a distribution network, contributes to the significant reduction of energy losses in lines, the improvement of the voltage profile and stability, as well as an increase in the manager's profit margin. This project has a very interesting benefit-cost ratio and may well be the subject of a detailed financial study to serve as decision-making tools for donors.

\section{References}

[1] Abhilipsa Rath, Sriparna Roy Ghatak, Parag Goyal, "Optimal allocation of Distributed Generation (DGs) and static VAR compensator (SVC) in a power system using Revamp Voltage Stability Indicator", In 2016 National Power Systems Conference (NPSC), pages 1-6, Bhubaneswar, India, December 2016. IEEE.

[2] Duong Quoc Hung, N. Mithulananthan, Kwang Y. Lee, “Optimal placement of dispatchable and nondispatchable renewable DG units in distribution networks for minimizing energy loss", Electrical Power and Energy Systems 55 (2014) 179-186.

[3] Srinivas Nagaballi, Vijay S. Kale, «Application of Metaheuristic Algorithms for Optimal Allocation of DGs in Radial Distribution System», International Journal of Engineering Research in Computer Science and Engineering (IJERCSE), Vol 5, Issue 2, February 2018.

[4] P. Dinakara Prasasd Reddy, V. C. Veera Reddy, T. Gowri Manohar, "Ant Lion optimization algorithm for optimal sizing of renewable energy resources for loss reduction in distribution systems", Journal of Electrical Systems and Information Technology (2017).

[5] Athira Jayavarma, Tibin Joseph, Sasidharan Sreendharan, «Optimal Placement of Fuel Cell DG and Solar PV in Distribution System using Particle Swarm Optimization», IJSER, Volume 4, Issue 9, September - 2013.

[6] Ebrahim Farjah, Mosayeb Bornapour, Taher Niknam, Bahman Bahmanifirouzi, «Placement of Combined Heat, Power and Hydrogen Production Fuel Cell Power Plants in a Distribution Network», Energies 2012, 5, 790-814.

[7] Minh Quan Duong, Thai Dinh Pham, Thang Trung Nguyen, Anh Tuan Doan, Hai Van Tran, «Determination of Optimal Location and Sizing of Solar Photovoltaic Distribution
Generation Units in Radial Distribution Systems», Energies 2019, 12, 174.

[8] Majid Aryanezhad, Elahe Ostadaghaee, Mahmood Joorabian, «Optimal Allocation and sizing of FACTS Devices Based Non-dominated Sorting Genetic Algorithm II», The 1st Iran Energy Association National Conference - 2013 Tehran, No. 13-EN-EPP-1242.

[9] Walaa Ahmed, Ali Selim, Salah Kamel, Juan Yu, Francisco Jurado, «Probabilistic Load Flow Solution Considering Optimal Allocation of SVC in Radial Distribution System», International Journal of Interactive Multimedia and Artificial Intelligence, Vol. 5, No. 3.

[10] Mohamad Khairuzzaman Mohamad Zamani, Ismail Musirin, and Saiful Izwan Suliman, «Symbiotic Organisms Search Technique for SVC Installation in Voltage Control», Indonesian Journal of Electrical Engineering and Computer Science, 6 (2): 318, May 2017.

[11] Thishya Varshitha U., Balamurugan K., «Optimal placement of distibuted generation with SVC for power loss reduction in distributed system», ARPN Journal of Engineering and Applied Sciences, Vol. 1, No. 17, September 2017.

[12] A. Rath, S Roy Ghatak, «Technical and Economic Assessment of Power System by Incorporating Distributed Generation and Static VAR Compensator», Smart Grid, 3 (1): 6, 2016.

[13] Ali Ehsan, Qiang Yang, "Coordinated Investment Planning of Distributed Multi-Type Stochastic Generation and Battery Storage in Active Distribution Networks", Transactions on Sustainable Energy, 2018 IEEE.

[14] Carlos D. Rodríguez-Gallegos, Dazhi Yang, Oktoviano Gandhi, Monika Bieri, Thomas Reindl, S. K. Panda, «A multiobjective and robust optimization approach for sizing and placement of PV and batteries in off-grid systems fully operated by diesel generators: An Indonesian case study», Energy 160 (2018) 410-429.

[15] A. OLOULADE, A. MOUKENGUE IMANO, A. VIANOU, R. BADAROU, «Contribution à l'étude de la répartition de puissance et à l'évaluation des pertes dans les réseaux de transport et de distribution de la communauté électrique du Bénin et de la société béninoise d'énergie électrique (CEBSBEE)», Sciences, Technologies et Développement, Edition spéciale, pp 8è-90, Juillet 2016.

[16] Kabir A. MA, Abubakar A. S., Abdulrahman O., Salisu S., «A Matlab Based Backward-forward Sweep Algoritm for Radial Distribution Network Power Flow Analysis», IJSEI vol. 4, issue 46, November 2015.

[17] Nangboguina Madjissembay, Christopher M. Muriithi, C. W. Wekesa, «Load Flow Analysis for Radial Distribution Networks Using Backward/Forward Sweep Method», Open Access Journal, JSRE, Vol. 3 (3) 2016, 82-87.

[18] Thang VU, «Répartition des moyens complémentaires de production et de stockage dans les réseaux faiblement interconnectés ou isolés», U. Grenoble, Thèse, Février 2011

[19] R. RANJAN \& D. DAS (2003): «Voltage Stability Analysis of Radial Distribution Networks», Electric Power Components and Systems, 31: 5, 501-511.

[20] Gundugallu Peddanna, Y. Siva Rama Kishore, «Power Loss Allocation of Balanced Radial Distribution Systems», IJSR, Index Copernicus Value (2013): 6.14 | Impact Factor (2013): 4.438 . 
[21] Herman Amour Vidjinnangni TAMADAHO, «Optimisation du positionnement d'un D-STATCOM dans un réseau radial de distribution pour l'amélioration des performances techniques du réseau HTA de Togba de la commune d'Abomey-Calavi», p. 113, UAC-EPAC, 2016-2017.

[22] Adrien BIO YATOKPA, Sakariyou MAHMAN, Koffi ABBLE, «Identification et catographie des potentialités et sources d'énergies renouvelables assorties des possibilités d'exploitation», PNUD, Juillet 2010.
[23] Barrios-Martinez E., Angeles-Camacho C., «Technical comparaison of FACTS controllers in parallel connection», Jornal of Applied Research and Technology (2017).

[24] Reza SIRJANI, Azak MOHAMED, Hussain SHAREEF, «Optimal placement and sizing of Static Var Compensator in power systems using Improved Harmony Search Algorithm», University Kebangsaan Malaysia (UKM). 